\title{
An Energy-Based Safety Evaluation Index of Blast Vibration
}

\author{
Mingsheng Zhao, ${ }^{1}$ Dong Huang, ${ }^{2}$ Maosen Cao, ${ }^{3}$ En-an Chi, ${ }^{4}$ Jun Liu, ${ }^{5}$ and Qiang Kang ${ }^{6}$ \\ ${ }^{1}$ Guizhou Xinlian Blasting Engineering Group Co. Ltd., 78 Xinhua Road, Fuzhong Building 17, Guiyang, Guizhou 550002, China \\ ${ }^{2}$ Key Laboratory of Mountain Hazards and Surface Process and Institute of Mountain and Environment, Chinese Academy of \\ Science and Ministry of Water Conservancy, Chengdu, Sichuang 610041, China \\ ${ }^{3}$ College of Mechanics and Materials, Hohai University, 1 Xikang Road, Nanjing, Jiangsu 210098, China \\ ${ }^{4}$ Guizhou Xinlian Blasting Engineering Group Co. Ltd. and Mining College, Guizhou University, 78 Xinhua Road, \\ Fuzhong Building 17, Guiyang, Guizhou 550002, China \\ ${ }^{5}$ Key Laboratory of Ministry of Education for Geomechanics and Embankment Engineering and Institute of Engineering Safety and \\ Disaster Prevention, Hohai University, 1 Xikang Road, Nanjing, Jiangsu 210098, China \\ ${ }^{6}$ Institute of Geotechnical Engineering, Hohai University, 1 Xikang Road, Nanjing, Jiangsu 210098, China
}

Correspondence should be addressed to Dong Huang; hd1017@sohu.com

Received 14 October 2014; Accepted 25 March 2015

Academic Editor: Mohammad Reza Ashoori

Copyright ( 2015 Mingsheng Zhao et al. This is an open access article distributed under the Creative Commons Attribution License, which permits unrestricted use, distribution, and reproduction in any medium, provided the original work is properly cited.

\begin{abstract}
The combined peak particle velocity (PPV) and frequency safety criterion for blast vibration is widely used in blasting engineering. However, some field investigations are inconsistent with this criterion. On the basis of field investigations, it is found that there are two failure modes of structures subjected to blasting seismic waves, that is, first-excursion failure and cumulative plastic damage failure. Moreover, the nature of structural responses under blast vibrations is a process of energy input, transformation, and dissipation. Therefore, an energy-based dual safety standard is proposed in this work to more comprehensively explain all failure modes of structures under blast vibrations. To this end, structures are simplified into elastic-plastic single degree of freedom (SDOF) systems with bilinear restoring force models, and energy responses of SDOF systems are then determined using the Newmark- $\beta$ method. From the energy responses, the maximum instantaneous input energy and hysteretic energy are selected as the basis of the dual safety criterion, because they can reflect first-excursion failure and cumulative plastic damage failure, respectively. Finally, field investigations in a blasting site in Zunyi, Guizhou province, China, are used to prove that compared to the PPV-frequency criterion the proposed energy-based dual safety criterion is more capable of assessing the damage potential of blast vibrations.
\end{abstract}

\section{Introduction}

Bench blasting with medium to deep blast holes is used increasingly in China in the current mining industry, infrastructure construction, and buildings demolition in cities. Blasting expedites the progress of construction and improves productivity. However, adverse effects of blasting (such as ground vibration, flying rocks, noise, etc.) are inevitable and should be minimized to a permissible level. Among all the adverse effects, ground vibration is a prime concern, attracting considerable research effort.

Based on extensive field investigations, early studies of structural responses and damage from blast-induced ground vibration focused on establishing empirical allowable ground vibration levels in terms of either peak particle velocities (PPV) [1-4] or PPV together with the principal ground vibration frequency (the so-called PPV-frequency criterion) to limit structural damage $[5,6]$. As these two criteria can be easily implemented, they have been adopted in the national standards of many countries [7]. For example, the PPVfrequency criterion is recommended by the latest Chinese standard (GB6722-2003) [8]. Therefore, in research into blast-induced ground vibration, efforts are still exerted to precisely predict PPV under different circumstances [9-11] and to propose a more accurate PPV-frequency criterion for specific categories of buildings [7]. In this criterion, however, the shapes of wave forms, the duration of dynamic loading, and the dynamic responses of structures are not taken into 
account. Thus the PPV-frequency criterion still has limitations in controlling permissible ground vibrations. Because energy is capable of representing the resultant action of the amplitude, frequency, and duration of blast-induced ground vibrations, energy-based failure criteria have been proposed to assess the damage to buildings subjected to blast vibrations. For example, equivalent energy proposed by Wenhua et al. [12], response energy by Guosheng et al. [13], equivalent peak energy by Li et al. [14], maximum instantaneous input energy by Zhang et al. [15], and total input energy by Wang et al. [16] have been, respectively, suggested as failure criteria for buildings. These works more comprehensively reflect the failure process of buildings subjected to blast vibrations. It should be borne in mind that the nature of structural responses under blast vibrations is a process of energy input, transformation, and dissipation. The structural responses depend not only on input blasting seismic waves, but also on the parameters of structures, such as natural period, damping ratio, yield strength factor, and stiffness reduction factor $[17,18]$. Therefore, the accuracy of failure criteria that are simple additive weighted energy based on either different frequency bands or different intrinsic mode function (IMF) components of blasting seismic waves is still questioned.

From the viewpoint of energy analysis in elastoplastic structures, energy is continuously transferred from seismic waves to structures in natural earthquakes. A proportion of energy is stored as recoverable kinetic energy and elastic strain energy, and the rest is dissipated by damping and hysteretic energy of plastic deformation. As the damping ratios of structures vary over a small range, hysteretic energy is regarded as the most important energy index of the cumulative plastic damage of structures $[19,20]$. By analogy, hysteretic energy can also be used to indicate the cumulative damage of structures subjected to blast vibrations. Research into speed pulse earthquakes [21, 22] has shown that the maximum instantaneous input energy (MIIE) transferred into structures occurs at the position of speed pulses and is very likely to cause the maximum displacement and the first-excursion failure of structures. Researchers [23-25] have demonstrated that MIIE is closely related to the maximum displacement of a structure, and thus MIIE can indicate the first-excursion failure of structures under earthquake.

There are two primary types of structural failure under blast vibrations, namely, first-excursion failure and cumulative plastic failure. These two failures result from both the characteristics of blast vibrations and the dynamic responses of structures $[15,16]$. MIIE fails to show the cumulative effect of the duration of ground vibrations on the nonlinear plastic deformations of structures [25], and hysteretic energy scarcely reflects first-excursion failure of structures caused pulse-like ground motions [26, 27]. Therefore, a dual failure (or safety) criterion is often used in seismic design in earthquake engineering $[28,29]$. Investigations of blast vibrations have shown that the failure mechanisms of structures subjected to blast vibrations and natural earthquakes are similar $[14,15,30]$. In this paper, therefore, a dual safety criterion is proposed to more comprehensively assess the damage potential of structures under blast vibrations. To this end, (1) buildings affected by blast vibrations are simplified into elastoplastic single degree of freedom (SDOF) systems with bilinear hysteretic restoring forces, and the corresponding structural energy responses are analyzed using the Newmark$\beta$ method; (2) MIIE and hysteretic energy are proposed as a dual safety criterion for structures, as they reflect firstexcursion failure and cumulative plastic failure, respectively.

\section{Hysteretic Energy of Structures}

2.1. Concept of Hysteretic Energy. In a SDOF system, the relative energy equation of a unit mass structure at time $t$ is

$$
\begin{gathered}
\int_{0}^{t} m \ddot{U}(t) \dot{U}(t) d t+\int_{0}^{t} c(\dot{U}(t))^{2} d t+\int_{0}^{t} F(U(t)) \dot{U}(t) d t \\
=\int_{0}^{t}-m \ddot{U}_{g}(t) \dot{U}(t) d t,
\end{gathered}
$$

where $\ddot{U}(t), \dot{U}(t)$, and $U(t)$ are the relative acceleration, velocity, and displacement between the structure and the ground, respectively; $F(U(t))$ is the restoring force; $c$ is the damping coefficient; $m$ is the mass of the block in SDOF; $\ddot{U}_{g}(t)$ is the ground acceleration induced by blast vibration. Assuming a bilinear hysteretic restoring force model and a dividing mass $m$ at both sides of (1a), (1a) becomes

$$
\begin{gathered}
\int_{0}^{t} \ddot{U}(t) \dot{U}(t) d t+\int_{0}^{t} 2 \xi \omega(\dot{U}(t))^{2} d t+\int_{0}^{t} p \omega^{2} \dot{U}(t) d t \\
=\int_{0}^{t}-\ddot{U}_{g}(t) \dot{U}(t) d t,
\end{gathered}
$$

where $\xi=c /(2 m \omega)$ is the structure damping ratio, typically assumed as a constant; $\omega=\omega_{0} \sqrt{1-\xi^{2}}$ is the natural frequency of the damped structure and $\omega_{0}=\sqrt{k / m}$ is the natural frequency without damping; $\omega \approx \omega_{0}$ when $\xi \ll 1 ; p$ is the stiffness ratio in the bilinear hysteretic restoring force model, $p=1$ for the elastic stage and $p=k_{i} / k$ for the plastic stage, where $k$ is the initial elastic stiffness and $k_{i}$ is the stiffness after yielding.

Equation (1b) is alternatively expressed as

$$
E_{K}+E_{D}+E_{H}+E_{E}=E_{I},
$$

where $E_{K}=\int_{0}^{t} \ddot{U}(t) \dot{U}(t) d t$ is the kinetic energy of the structure; $E_{D}=\int_{0}^{t} 2 \xi \omega(\dot{U}(t))^{2} d t$ is the damping energy dissipation of the structure; $E_{H}+E_{E}=\int_{0}^{t} p \omega^{2} \dot{U}(t) d t$ is the deformation energy, that is, the sum of hysteretic energy $E_{H}$ and elastic strain energy $E_{E}$, and $E_{H}=0$ for an elastic system; $E_{I}=\int_{0}^{t}-\ddot{U}_{g}(t) \dot{U}(t) d t$ is the total input energy of the system. Research [20] has shown that the proportion of $E_{E}$ in the deformation energy of an elastic-plastic structure is so small that $E_{E}$ can be ignored, and thus $E_{H}$ can represent the deformation energy.

2.2. Restoring Force Model of Structures. Restoring force is structural resistance against deformation. The curve of 


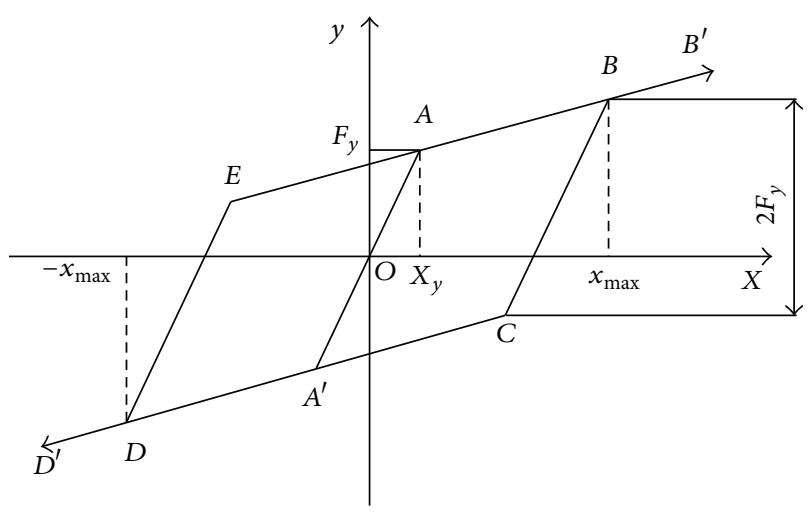

FIGURE 1: Bilinear restoring force model.

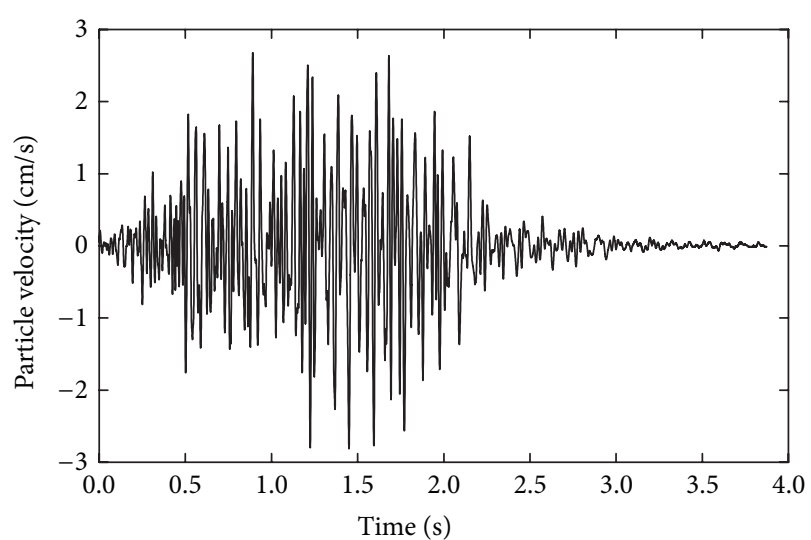

FIGURE 2: A velocity waveform measured in an open pit induced by a blast.

$$
\begin{aligned}
& \Delta U=-\Delta \ddot{U}_{g}+\frac{1}{\beta \Delta t} \dot{U}_{n}+\frac{1}{2 \beta} \ddot{U}_{n} \\
&\left.+4 \xi \omega_{0}\left(\frac{1}{2 \beta} \dot{U}_{n}+\left(\frac{1}{4 \beta}-1\right) \ddot{U}_{n} \Delta t\right)\right) \\
& \cdot\left(p \omega_{0}^{2}+\xi \omega_{0} \frac{1}{\beta \Delta t}+\frac{1}{\beta \Delta t^{2}}\right)^{-1}, \\
& \Delta \dot{U}= \frac{1}{2 \beta \Delta t} \Delta U-\frac{1}{2 \beta} \dot{U}_{n}-\left(\frac{1}{4 \beta}-1\right) \ddot{U}_{n} \Delta t, \\
& \Delta \ddot{U}=\frac{1}{\beta \Delta t^{2}} \Delta U-\frac{1}{\beta \Delta t} \dot{U}_{n}-\frac{1}{2 \beta} \ddot{U}_{n},
\end{aligned}
$$

where $\ddot{U}_{n}, \dot{U}_{n}$, and $U_{n}$ are the acceleration, velocity, and displacement at the previous time step, respectively.

Following the above algorithm, the measured data of an open-pit mine is selected as an example to demonstrate the energy responses of a structure subjected to blast vibrations. Figure 2 shows the measured blast vibration velocity signal with a sampling frequency of $2000 \mathrm{~Hz}$. The affected structure is assumed to be a unit mass elastoplastic SDOF system with a damping ratio of $\xi=0.05$ and a natural period of $T=0.1 \mathrm{~s}$. The yield strength coefficient of the bilinear restoring force model is 0.3 (equal to the ratio of $x_{y} / x_{\max }$ ), and the stiffness reduction factor after yielding (i.e., $\alpha$ ) is 0.02 . Thereafter, in accordance with (1b), the incremental quantities in 2.3 are integrated step by step to obtain the total input energy $\left(E_{I}\right)$, the kinetic energy $\left(E_{k}\right)$, the deformation energy $\left(E_{E}+\right.$ $\left.E_{H}\right)$, and the damping energy dissipation $\left(E_{D}\right)$ of the SDOF system. The time histories of these energies are shown in Figure 3. Further, the time histories of the percentages of $E_{k}$, $E_{E}+E_{H}$, and $E_{D}$ to the total input energy $E_{I}$ are shown in Figure 4.

From Figures 3 and 4, the following can be found: (1) Responses of input energy, damping energy, and hysteretic energy of a structure are gradual process of accumulation. These three energies all increase with time and attain their maximum values at the end of the blast vibration. are given by 


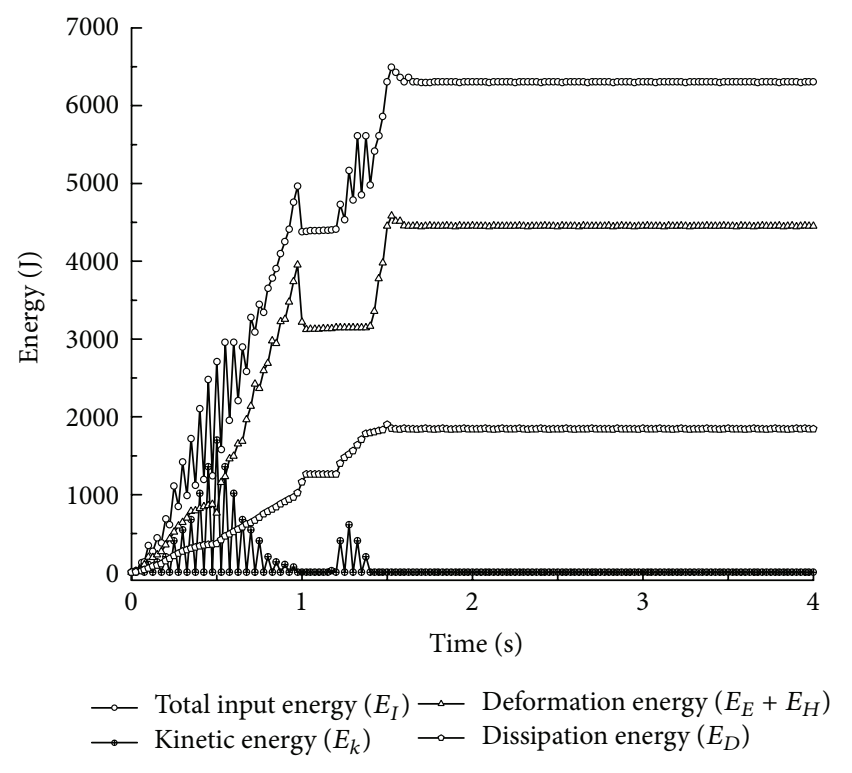

FIgURE 3: Time histories of energy responses in elastoplastic structure.

(2) The energy of an elastoplastic SDOF structure under blast vibrations consists of input energy, kinetic energy, deformation energy, and damping energy. With an increase in vibration duration, kinetic energy and elastic strain energy of deformation energy undergo mutual transformation and eventually tend to 0 . At the end of the blast vibration, all the input energy is dissipated by hysteretic energy of plastic deformations and damping energy. (3) With an increase of the duration of blast vibration, the percentages of hysteretic energy and damping energy to total input energy tend to be stable, at around $70 \%$ and $30 \%$, respectively, as shown in Figure 4. As hysteretic energy dominates the energy dissipation in the hardening stage of structural nonlinear responses, it can be used for assessing the cumulative plastic damage of structures under blasting vibration.

\section{Maximum Instantaneous Input Energy of Structures}

3.1. Definition of Instantaneous Input Energy. The input energy between two adjacent zero-velocity points in a structural energy response is defined as instantaneous input energy, $\Delta E$. Due to zero-velocity between the two adjacent points, the incremental kinetic energy is null, and thus (lb) can be written as

$$
\begin{gathered}
\int_{t}^{t+\Delta t} 2 \xi \omega(\dot{U}(t))^{2} d t+\int_{t}^{t+\Delta t} p \omega^{2} \dot{U}(t) d t \\
=\int_{t}^{t+\Delta t}-\ddot{U}_{g}(t) \dot{U}(t) d t,
\end{gathered}
$$

where time interval $\Delta t$ is the time needed in a half cycle of structural vibration and $\Delta t$ is not a constant value, because of the nonstationary random characteristics of blasting seismic

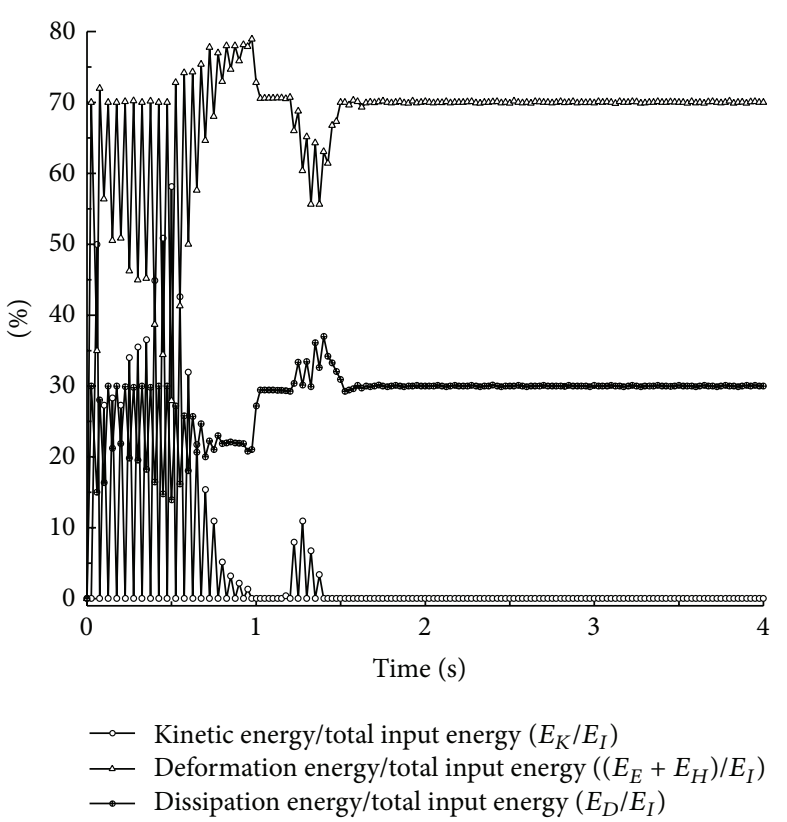

FIGURE 4: Time histories of percentages of structural energies to total input energy.

waves. The energy equation can be expressed by (5) according to (2); that is,

$$
\Delta E_{D}+\left(\Delta E_{H}+\Delta E_{E}\right)=\Delta E_{I} .
$$

Good correlation has been found between MIIE $\Delta E_{I \max }$ and the maximum displacement of a structure over a short period of vibration [32-34]. Because the dominant frequencies of blasting seismic waves are higher than those of natural earthquakes, structural responses to blasting seismic waves occur mainly in over short period range $[35,36]$. Accordingly, the MIIE of elastoplastic structural responses obtained by using bilinear restoring force models in this paper can accurately indicate the first-excursion failure of a structure subjected to blasting seismic waves.

3.2. Calculation of Instantaneous Input Energy. According to the definition of instantaneous input energy (IIE), points with zero-velocity are selected from the time history of velocity as shown in Figure 2. The differences of input energy $E_{I}$ in the time intervals between each two adjacent selected points are calculated to establish the time history of IIE, as shown in Figure 5. The maximum value in Figure 5 is the MIIE.

Figure 5 shows that the MIIE affects structures for a very short time, less than $1.5 \mathrm{~s}$. However, the dissipation of input energy due to damping is a process of accumulation (from $0 \mathrm{~s}$ to $4 \mathrm{~s}$ ), as shown in Figure 3. Therefore, if the IIE is too large, a structure may fail in a short time due to large deformations, prior to the excitation of damping. Therefore, the first failure of structures caused by MIIE under blasting seismic waves plays an important role in situations of a small distance from an explosive charge center. According to the definition and the calculation of MIIE, MIIE is mainly affected by PPV and the dominant frequencies of blasting seismic waves as 


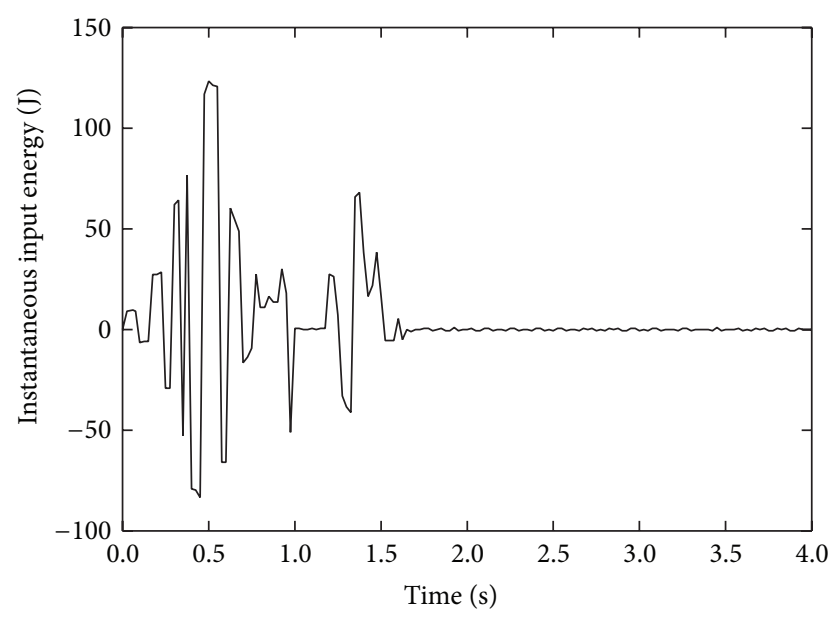

FIGURE 5: Time history of instantaneous input energy.

well as by the natural periods of structures. Nevertheless, the duration of blasting seismic waves has no effect on MIIE. Consequently, MIIE cannot reflect the cumulative effect of blasting seismic waves on structure failure.

Following the above analysis, MIIE can reflect the firstexcursion failure of structures under blasting seismic waves, and hysteretic energy is an important index of the cumulative plastic damage in structures. Therefore, MIIE and hysteretic energy are proposed as a dual safety criterion for structures subjected to blast vibrations.

\section{Dynamic Parameters of Structures}

The primary structural parameters that affect MIIE and hysteretic energy are the natural periods and damping ratios of structures. Damping ratios are usually assumed to be constant in structural dynamic analysis, ranging within 0.02 0.05 for typical building structures. A damping ratio of 0.05 has been used in analyzing structural responses under blasting seismic waves $[13,15,16,35]$, so the damping ratio in this paper is also assumed to be 0.05 in assessing the damage potential caused by blast vibrations. There are two methods to determine the natural periods of structures, namely, theoretical calculation and empirical formula, and the latter is preferred in engineering applications [13]. Most buildings analyzed in this paper are brick-concrete structures. Based on the derivation of uniform cantilever beams and the measurement of dynamic characteristics of multistory brick-concrete structures [13], the natural period of a brickconcrete structure is closely related to its height. In the general field, the natural period is estimated as

$$
T_{0}=0.0168(H+1.2),
$$

where $H$ is the height of a structure.

\section{Application of the Energy-Based Safety Evaluation Method}

5.1. Experimental Details. The proposed energy-based dual safety criterion was used in a series of bench blasts. The

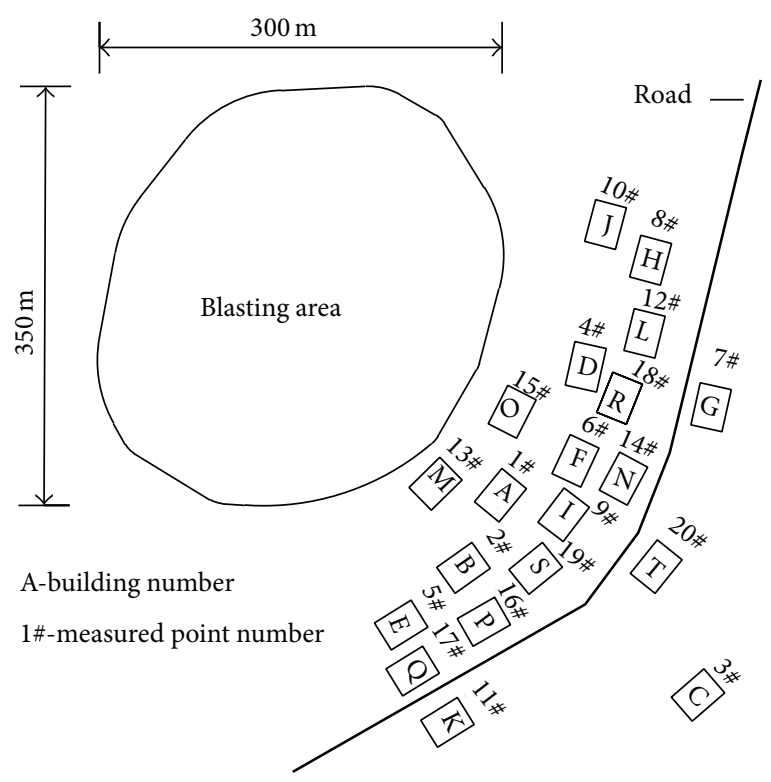

FIGURE 6: Buildings surrounding blasting area.

bench excavation elevation was $8 \mathrm{~m}$. Drilling equipment consisted of 351 down-the-hole drills and hydraulic drilling machines. There were three hole diameters, $90 \mathrm{~mm}, 115 \mathrm{~mm}$, and $140 \mathrm{~mm}$. Quincuncial hole arrangement and plastic Nonel tubes were used. Ten-period detonators were used with millisecond delays in each hole, three-period detonators were used with a millisecond delays every 2-3 holes, and fiveperiod detonators were used in millisecond delays between rows. Two types of explosives were utilized, including the mixed loading ANFO and the mixed loading emulsion explosive. The total charge amount each time was not greater than $12,000 \mathrm{~kg}$, and the maximum charge amount per delay was about $160 \mathrm{~kg}$.

The buildings in the surroundings of the blasting area are shown in Figure 6. It can be seen that residential buildings are extensively distributed around the blasting area. These buildings are typically two-story brick-concrete structures built at the beginning of this century. The floors in those buildings are constructed of precast panels that are basically not connected by ring beams. Therefore, the global seismic performance of these buildings is poor. Some residential buildings around the blasting area were not covered by land requisition schemes and hence were still in use during the blasting construction period. As a result, it was necessary to assess and control the effects of blast vibrations on these residential buildings.

During blasting, a great many investigations were carried out to assess the possible damage to the residential buildings caused by blast vibration. To prove that the proposed dual safety criterion based on MIIE and hysteretic energy was superior to the PPV-frequency criterion, the measured data at the foundations of 20 residential buildings were selected for demonstration. The basic parameters and the conditions prior to blasting of these 20 residential buildings are given in Table 1 . The main parameters extracted from the measured 
TABLE 1: The main parameters of the surrounding buildings of the blasting area.

\begin{tabular}{lccc}
\hline $\begin{array}{l}\text { Building } \\
\text { number }\end{array}$ & $\begin{array}{c}\text { Types of } \\
\text { buildings }\end{array}$ & $\begin{array}{c}\text { Building } \\
\text { height }(\mathrm{m})\end{array}$ & Status before blast \\
\hline $\mathrm{A}$ & Brick-concrete & 7.3 & Intact \\
$\mathrm{B}$ & Brick-concrete & 7.5 & Intact \\
$\mathrm{C}$ & Brick-concrete & 7.1 & Intact \\
$\mathrm{D}$ & Brick-concrete & 7.3 & Intact \\
$\mathrm{E}$ & Brick-concrete & 7.0 & Intact \\
$\mathrm{F}$ & Brick-concrete & 7.1 & Intact \\
$\mathrm{G}$ & Brick-concrete & 7.4 & Intact \\
$\mathrm{H}$ & Brick-concrete & 7.8 & Intact \\
$\mathrm{I}$ & Brick-concrete & 7.6 & Intact \\
$\mathrm{J}$ & Brick-concrete & 7.6 & Intact \\
$\mathrm{K}$ & Brick-concrete & 12.5 & Intact \\
$\mathrm{L}$ & Brick-concrete & 7.2 & Intact \\
$\mathrm{M}$ & Brick-concrete & 7.3 & Intact \\
$\mathrm{N}$ & Brick-concrete & 7.5 & Intact \\
$\mathrm{O}$ & Brick-concrete & 7.5 & Intact \\
$\mathrm{P}$ & Brick-concrete & 7.4 & Intact \\
$\mathrm{Q}$ & Brick-concrete & 7.7 & Tiny crack on \\
$\mathrm{R}$ & Brick-concrete & 11.4 & wall \\
$\mathrm{S}$ & Brick-concrete & 7.2 & Intact \\
$\mathrm{T}$ & Brick-concrete & 7.0 & Tiny crack on \\
\hline & & & Intact \\
\hline
\end{tabular}

results are listed in Table 2. These results are discussed by the aforementioned two criteria later.

5.2. Analysis Based on the PPV-Frequency Safety Standard. The latest national safety regulations for blasting (GB67222003) were issued in 2003 [8]. The regulations adopted the PPV-frequency safety standard (as shown in Table 3) to assess the damage potential for buildings subjected to blast vibrations.

The dominant frequencies of blasting seismic waves were in the range $10-50 \mathrm{~Hz}$ at the measuring points $1 \#, 4 \#, 13 \#$, and 15\# (see Table 2), where all the tested buildings tested were brick-concrete structures. According to Table 3, the maximum allowable PPV was $2.8 \mathrm{~cm} / \mathrm{s}$. All the measured velocities at these four points have exceeded $2.8 \mathrm{~cm} / \mathrm{s}$ (see Table 2). After blasting, no damage was found in residential buildings $\mathrm{A}$ and $\mathrm{D}$ corresponding to measuring points $1 \#$ and $4 \#$, respectively. Buildings $\mathrm{M}$ and $\mathrm{O}$ at measuring points $13 \#$ and 15\# were nearer to the blasting area and had already been abandoned prior to blasting. After blasting, it was found that in building $M$ that a large area of floated coat had chipped off, " $X$ " shaped cracks had formed on the windowsills and doorways, and many cracks occurred on the walls and the floors. In building $\mathrm{O}$ after blasting, it was observed that the floated coat had chipped off, cracks appeared on the walls, and a horizontal crack occurred at a staircase. The dominant frequency of the blast seismic wave at measuring point 10\# was $9.519 \mathrm{~Hz}$, and the maximum allowable PPV was $2.5 \mathrm{~cm} / \mathrm{s}$ according to Table 3 . However, the measured PPV was $2.7 \mathrm{~cm} / \mathrm{s}$, and no damage was found in the corresponding residential building $\mathrm{J}$ at measuring point $10 \#$.

All the PPVs of the other measuring points were lower than the corresponding maximum allowable PPVs. Nevertheless, in building $\mathrm{P}$ at measuring point 16\#, the floating coat had chipped off and cracks appeared on the windowsills; in building $\mathrm{Q}$ at point 17\#, original tiny cracks had broadened; in building $S$ at point 19\#, the floating coat had chipped off, original tiny cracks had widened, and new " $\mathrm{X}$ " shape cracks had developed in the doorways.

In summary, the measured PPVs at 15 buildings out of 20 were lower than the maximum allowable value, and no damage was found in 12 of those buildings. Although the measured PPVs in the other 5 buildings exceeded the allowable value, only 2 of them were damaged. The findings from 14 of the buildings can be explained by the safety level standard as shown in Table 3, indicating that the safety level standard based on extensive investigations of blasting vibrations could provide valuable suggestions. However, the findings from the other 6 buildings were beyond the current national safety level standard. These differences are ascribed to the facts that (1) the current standard only considers the PPV and the dominant frequency of a blasting seismic wave, without accounting for the duration of the blasting seismic wave and the associated structural responses and (2) the current standard permits reduction of the allowable PPVs for old and originally damaged buildings but has no clear quantitative specifications for the reduction.

5.3. Analysis Using the Energy-Based Safety Evaluation Method. For comparison with the analysis based on the PPV-frequency safety standard, the measured data from 20 buildings was also analyzed using the proposed dual safety criterion based on MIIE and hysteretic energy. Because all the residential buildings were brick-concrete structures, their natural vibration periods were obtained by (6). In addition, it was assumed that, for all 20 buildings, the damping ratios were 0.05 , the yield strength coefficient of the bilinear restoring force model was 0.3 , and the stiffness reduction factor after yielding was 0.02. Following the procedures illustrated in Sections 2 and 3, the MIIE and the hysteretic energy of the 20 structures under blasting seismic waves were calculated and are shown in Table 4.

MIIE is mainly related to the PPV and dominant frequency of a blasting seismic wave and the natural periods of vibrated structures but is unable to reflect the adverse effect of the duration of blasting vibration. In contrast, hysteretic energy can account for the effects of the vibration duration. For example, Table 4 shows that the MIIEs at measuring points $13 \#$ and $15 \#$ are $220.25 \mathrm{~J}$ and $215.11 \mathrm{~J}$, respectively, much higher than those at the other points. However, the hysteretic energies at points $13 \#$ and $15 \#$ are $2987.19 \mathrm{~J}$ and $2853.33 \mathrm{~J}$, respectively, smaller than that at point $16 \#$ $(3022.22 \mathrm{~J})$. The maximum MIIEs at measuring points 16\#, 17\#, and 19\# are $155.54 \mathrm{~J}, 113.17 \mathrm{~J}$, and $103.22 \mathrm{~J}$, respectively, and the corresponding hysteretic energies are 3022.22 J, 2930.09 J, and $2853.87 \mathrm{~J}$, respectively. Except for the above-mentioned 
TABle 2: The results measured at the buildings.

\begin{tabular}{|c|c|c|c|c|c|}
\hline $\begin{array}{l}\text { Measured } \\
\text { point number }\end{array}$ & $\begin{array}{c}\text { Maximum charge } \\
\text { per delay }(\mathrm{kg})\end{array}$ & $\begin{array}{c}\text { Distance from } \\
\text { explosion source }(\mathrm{m})\end{array}$ & $\operatorname{PPV}(\mathrm{cm} / \mathrm{s})$ & $\begin{array}{c}\text { Dominant frequency } \\
(\mathrm{Hz})\end{array}$ & Duration (s) \\
\hline $1 \#$ & 120 & 55.12 & 3.035 & 29.608 & 1.6 \\
\hline $2 \#$ & 85 & 83.44 & 1.693 & 11.576 & 0.7 \\
\hline $3 \#$ & 140 & 273.87 & 0.702 & 24.691 & 1.2 \\
\hline $4 \#$ & 160 & 64.32 & 2.839 & 27.454 & 2.5 \\
\hline $5 \#$ & 110 & 88.53 & 1.427 & 21.277 & 2.2 \\
\hline $6 \#$ & 60 & 91.65 & 1.510 & 21.677 & 2.5 \\
\hline $7 \#$ & 80 & 152.39 & 0.827 & 9.412 & 1.0 \\
\hline $8 \#$ & 60 & 98.11 & 1.164 & 13.519 & 2.5 \\
\hline 9\# & 110 & 103.25 & 1.137 & 31.250 & 1.6 \\
\hline $10 \#$ & 140 & 96.38 & 2.731 & 9.519 & 0.7 \\
\hline $11 \#$ & 120 & 162.84 & 0.608 & 8.333 & 2.1 \\
\hline $12 \#$ & 110 & 103.96 & 1.126 & 17.478 & 2.2 \\
\hline $13 \#$ & 60 & 10.16 & 5.916 & 48.868 & 0.5 \\
\hline $14 \#$ & 132 & 124.48 & 1.619 & 14.286 & 1.0 \\
\hline $15 \#$ & 144 & 26.12 & 4.801 & 41.544 & 0.6 \\
\hline $16 \#$ & 148 & 120.49 & 1.423 & 9.957 & 4.7 \\
\hline $17 \#$ & 120 & 113.11 & 0.905 & 10.659 & 4.8 \\
\hline $18 \#$ & 115 & 101.26 & 1.221 & 14.804 & 3.8 \\
\hline $19 \#$ & 135 & 113.45 & 1.092 & 9.241 & 3.4 \\
\hline $20 \#$ & 144 & 166.49 & 0.874 & 12.868 & 4.3 \\
\hline
\end{tabular}

TABLE 3: The safe level standard of blast vibrations in China (GB6722-2003).

\begin{tabular}{lccc}
\hline \multirow{2}{*}{ Types of structures } & \multicolumn{3}{c}{ Allowable PPV (cm/s) } \\
& $<10 \mathrm{~Hz}$ & $10-50 \mathrm{~Hz}$ & $50-100 \mathrm{~Hz}$ \\
\hline $\begin{array}{l}\text { Soil cave houses, adobe } \\
\text { houses, and rubble stone } \\
\text { structures }\end{array}$ & $0.5-1.0$ & $0.7-1.2$ & $1.1-1.5$ \\
$\begin{array}{l}\text { Common brick and large } \\
\text { nonseismic designed } \\
\text { masonry buildings }\end{array}$ & $2.0-2.5$ & $2.3-2.8$ & $2.7-3.0$ \\
$\begin{array}{l}\text { Reinforced concrete } \\
\text { framed structures }\end{array}$ & $3.0-4.0$ & $3.5-4.5$ & $4.2-5.0$ \\
$\begin{array}{l}\text { Common historical } \\
\text { buildings and interests }\end{array}$ & $0.1-0.3$ & $0.2-0.4$ & $0.3-0.5$ \\
$\begin{array}{l}\text { Hydraulic tunnels } \\
\text { Traffic tunnels }\end{array}$ & & $7-15$ & \\
Mine roadways & & $10-20$ & \\
\hline
\end{tabular}

5 points, the MIIEs and the hysteretic energies at all the other points are below $200 \mathrm{~J}$ and $3000 \mathrm{~J}$, respectively. Moreover, no damage was found in the buildings at these 15 points. Prior to blasting, some tiny cracks had already occurred on the walls of residential buildings $\mathrm{Q}$ and $\mathrm{S}$ at measuring points $17 \#$ and 19\#, respectively, and all the other 18 buildings were intact, as shown in Table 1. It is concluded, therefore, that (1) MIIE beyond $200 \mathrm{~J}$ caused the first-excursion failures of the intact residential buildings with brick-concrete structures, such as buildings $\mathrm{M}$ and $\mathrm{O}$ at measuring points 13\# and
$15 \#$, respectively; hysteretic energy beyond $3000 \mathrm{~J}$ resulted in cumulative plastic damage, such as in building $\mathrm{P}$ at point 16\#; (2) the threshold values of the MIIE and the hysteretic energy for the residential buildings with original tiny cracks were, respectively, lower than those of intact residential buildings. In this test, the hysteretic energies at points 17\# and 19\# were closer to the threshold value of the cumulative plastic failure of intact buildings. Therefore, the damage found in these two buildings can be tentatively regarded as cumulative plastic failure.

In summary, the dual safety criterion based on MIIE and hysteretic energy takes into account the combined effects of blast vibration characteristics and associated structural responses. Therefore, this criterion can explain phenomena that are inconsistent with the current PPV-frequency safe level standard and is more comprehensive than the current standard.

\section{Conclusions}

Because the PPV-frequency safety level standard does not take into consideration the shape and the duration of blasting seismic waves as well as the corresponding dynamic responses of structures, the standard is limited in its ability to assess the potential for damage to structures subjected to blast-induced ground vibrations. To address these shortcomings, in this paper the following steps took place. (1) Structures are simplified into elastoplastic SDOF systems with bilinear restoring force models. The energy responses of SDOF systems subjected to blast vibrations 
TABLE 4: Energy responses of the residential buildings.

\begin{tabular}{|c|c|c|c|c|}
\hline $\begin{array}{l}\text { Measured } \\
\text { points number }\end{array}$ & $\begin{array}{l}\text { Building } \\
\text { number }\end{array}$ & $\begin{array}{l}\text { Natural vibration } \\
\text { period (s) }\end{array}$ & $\begin{array}{l}\text { Maximum instantaneous } \\
\text { input energy }(\mathrm{J})\end{array}$ & Hysteretic energy $(\mathrm{J})$ \\
\hline $1 \#$ & A & 0.1428 & 123.12 & 2745.44 \\
\hline 2\# & $\mathrm{B}$ & 0.1462 & 45.98 & 854.35 \\
\hline 3\# & $\mathrm{C}$ & 0.1394 & 17.33 & 356.32 \\
\hline $4 \#$ & $\mathrm{D}$ & 0.1428 & 131.44 & 2678.21 \\
\hline $5 \#$ & $\mathrm{E}$ & 0.1378 & 33.65 & 677.93 \\
\hline $6 \#$ & $\mathrm{~F}$ & 0.1394 & 34.13 & 768.86 \\
\hline $7 \#$ & G & 0.1445 & 20.66 & 459.19 \\
\hline $8 \#$ & $\mathrm{H}$ & 0.1512 & 31.28 & 679.37 \\
\hline 9\# & $\mathrm{I}$ & 0.1478 & 35.76 & 712.21 \\
\hline $10 \#$ & $\mathrm{~J}$ & 0.1478 & 119.76 & 2338.91 \\
\hline $11 \#$ & $\mathrm{~K}$ & 0.2302 & 35.67 & 697.44 \\
\hline $12 \#$ & $\mathrm{~L}$ & 0.1411 & 40.13 & 754.35 \\
\hline $13 \#$ & M & 0.1428 & 220.25 & 2987.19 \\
\hline $14 \#$ & $\mathrm{~N}$ & 0.1462 & 39.77 & 732.87 \\
\hline $15 \#$ & $\mathrm{O}$ & 0.1462 & 215.11 & 2853.33 \\
\hline $16 \#$ & $\mathrm{P}$ & 0.1445 & 155.54 & 3022.22 \\
\hline $17 \#$ & $\mathrm{Q}$ & 0.1495 & 113.17 & 2930.09 \\
\hline $18 \#$ & $\mathrm{R}$ & 0.2117 & 145.76 & 2871.15 \\
\hline $19 \#$ & S & 0.1411 & 103.22 & 2853.87 \\
\hline $20 \#$ & $\mathrm{~T}$ & 0.1378 & 143.23 & 2973.12 \\
\hline
\end{tabular}

are then determined using the Newmark- $\beta$ method. Those energy responses more comprehensively show the combined effects of blasting seismic waves and associated structural responses on the damage to structures. (2) A dual safety criterion based on MIIE and hysteretic energy is proposed to explain the damage to structures under blast vibrations. Note that the damage incurred by some structures is inconsistent with the current PPV-frequency standard but can be understood well using the proposed criterion.

MIIE affects structures for a very short time, during which damping is not excited. Therefore, MIIE causes firstexcursion structural failure. MIIE is mainly affected by PPV and the dominant frequencies of blasting seismic waves as well as the natural period of structures but cannot reflect the cumulative effect of blasting seismic waves on structural failure. In contrast, hysteretic energy is an important index for showing cumulative plastic damage in structures. Typically, structures subjected to blasting seismic waves with long durations are more likely to fail through cumulative plastic damage. The case study presented in this paper shows that the proposed dual safety criterion based on MIIE and hysteretic energy can more comprehensively and reasonably explain findings from field investigations.

\section{Conflict of Interests}

The authors declare that there is no conflict of interests regarding the publication of this paper.

\section{Acknowledgments}

This work was supported by the grants from the Guizhou Science and Technology Plan Project (no. SY2010365), Key Industrial Research Project Supported by Science Technology Department of Guizhou Province (no. (2013) 3013), Guizhou Province Outstanding Young Scientific Talents Training Program Funded Projects (no. (2013) 30) and the National Natural Science Foundation of China (nos. 41301009 and 51174076), the International Cooperation Program of the Ministry of Science and Technology of China (Grant no. 2013DFA21720), and the National Science \& Technology Support Program during the Twelfth Five-Year Plan Period (Grant no. 2011BAK12B01). These grants are gratefully acknowledged.

\section{References}

[1] U. Langerfors, H. Westerberg, and B. Kihlstrom, "Ground vibration in blasting," Water Power, vol. 10, no. 9, pp. 335-424, 1958.

[2] A. T. Edwards and T. D. Northwood, "Experimental studies of the effects of blasting on structures," The Engineer, vol. 210, pp. 538-546, 1960.

[3] W. I. Duvall and D. E. Fogleson, "Review of criteria for estimating damage to residences from blasting vibrations," Report of Investigation BM-RI-5968, Bureau of Mines, College Park, Md, USA, 1962.

[4] T. D. Northwood, R. Crawford, and A. T. Edwards, "Blast vibrations and building damage," The Engineer, vol. 215, pp. 973978, 1963. 
[5] C. H. Dowding, Blast Vibration Monitoring and Control, Prentice-Hall, Englewood Cliffs, NJ, USA, 1985.

[6] C. H. Dowding, Construction Vibrations, Prentice-Hall, Upper Saddle River, NJ, USA, 1996.

[7] P. K. Singh and M. P. Roy, "Damage to surface structures due to blast vibration," International Journal of Rock Mechanics and Mining Sciences, vol. 47, no. 6, pp. 949-961, 2010.

[8] GB6722-2003, "China Safety regulations for blasting," 2003.

[9] M. Khandelwal and T. N. Singh, "Evaluation of blast-induced ground vibration predictors," Soil Dynamics and Earthquake Engineering, vol. 27, no. 2, pp. 116-125, 2007.

[10] H. Ak and A. Konuk, "The effect of discontinuity frequency on ground vibrations produced from bench blasting: a case study," Soil Dynamics and Earthquake Engineering, vol. 28, no. 9, pp. 686-694, 2008

[11] R. Nateghi, "Evaluation of blast induced ground vibration for minimizing negative effects on surrounding structures," Soil Dynamics and Earthquake Engineering, vol. 43, pp. 133-138, 2012.

[12] H. Wenhua, X. Quanjun, and S. Wei, "Application of wavelet transform in evaluation of blasting vibration damage," Engineering Blasting, vol. 7, no. 1, pp. 24-28, 2001.

[13] Z. Guosheng, F. Yingguang, and X. Guoyuan, "Safety criterion of blasting vibration for structure based on wavelet packet analysis," Chinese Journal of Geotechnical Engineering, vol. 7, no. 1, pp. 24-28, 2001.

[14] H.-T. Li, X.-G. Yang, W.-B. Lu, D.-Q. Shu, and J.-W. Zhou, "Safety assessment for structures under blasting vibration based on equivalent peak energy," Chinese Journal of Geotechnical Engineering, vol. 33, no. 5, pp. 821-825, 2011.

[15] Y. Zhang, B. Li, Y. Wang, and X. Li, "Model and calculation of momentary input energy of blast-induced vibration based on Hilbert spectrum," Mining Research and Development, vol. 29, no. 4, pp. 88-90, 2009.

[16] Z. Wang, X. Liang, Y. Chen, F. Li, and G. Liu, "Study of safety evaluation method of blasting vibration based on input energy," Chinese Journal of Rock Mechanics and Engineering, vol. 29, no. 12, pp. 2492-2499, 2010.

[17] B. Liu, M. Xiao, and M. Lai, "Distribution of earthquake total input energy of structures," Journal of Chongqing Jian Zhu University, vol. 18, no. 2, pp. 100-109, 1996.

[18] A. Erberik and H. Sucuoğlu, "Seismic energy dissipation in deteriorating systems through low-cycle fatigue," Earthquake Engineering and Structural Dynamics, vol. 33, no. 1, pp. 49-67, 2004.

[19] G. Manfredi, "Evaluation of seismic energy demand," Earthquake Engineering \& Structural Dynamics, vol. 30, no. 4, pp. 485-499, 2001.

[20] C.-H. Zhai, L.-L. Xie, and Z.-F. Wu, "Influence analysis on hysteretic-energy based on 1999 CM-Chi, Taiwan Earthquake," Journal of Harbin Institute of Technology, vol. 38, no. 1, pp. 59-62, 2006.

[21] H. Norio, T. Tomaya, and I. Norio, "Damaging properties of ground motions and response behavior of structures based on momentary energy response," in Proceedings of the 12th World Conference on Earthquake Engineering (WCEE '00), Auckland, New Zealand, 2000.

[22] Z. Qiong, W. Qiang, and C. Shaolin, "Characteristics of instantaneous input energy of ground motion containing velocity pulses," Industrial Building, vol. 39, supplement 1, pp. 186-190, 2009.
[23] R. Hu and Y. Wang, "A study on relation of instantaneous energy of earthquake strong motion and maximum displacement response of structures," Journal of Building Structures, vol. 21, no. 1, pp. 71-76, 2000.

[24] N. Makris and C. Black, "Dimensional analysis of inelastic structures subjected to near-fault ground motions," Tech. Rep. 03-05, Earthquake Engineering Research Center, University of California, Berkeley, Calif, USA, 2003.

[25] K. Chen, Z.-F. Liu, and P.-S. Shen, "Study on the duration spectra of structural momentary input energy response," Engineering Mechanics, vol. 28, no. 1, pp. 19-25, 2011.

[26] X. Ming-Kui, B. Shao-Liang, and L. Ai-Ming, "Maximum displacement estimation of seismic structures based on hysteresis energy," Journal of Chongqing University, vol. 26, no. 3, pp. 133137, 2003.

[27] R. Hu and Y. Wang, "Evaluation of long-period structural maximum displacement response on momentary input energy," Journal of HUST: Urban Science Edition, vol. 23, no. 4, pp. 100104, 2006.

[28] Y.-J. Park and A. H.-S. Ang, "Mechanistic seismic damage model for reinforced concrete," Journal of Structural Engineering (ASCE), vol. 111, no. 4, pp. 722-739, 1985.

[29] Y. Wang, "A review of seismic response spectra, time history analysis and energy method," Journal of Building Structures, vol. 21, no. 1, pp. 21-27, 2000.

[30] Z. Duo and Y. Shaoguo, "Difference and connection of earthquake vibration and blasting vibration influence on building," Open Mining Technology, vol. 16, no. 3, pp. 68-69, 2010.

[31] M. Sheng and Q. Luo, "Comparison of hysteretic energy spectra in Northridge and ChiChi earthquake," Journal of Tongji University (Natural Science), vol. 36, no. 10, pp. 1314-1319, 2008.

[32] Q. Liu, R. Zhou, and Y. Liu, "Research on relation between instantaneous energy spectrum of earthquake ground motion and displacement response of structures," Journal of Earthquake Engineering and Engineering Vibration, vol. 29, no. 5, pp. 46-51, 2009.

[33] W. Changfeng and Z. Dongsheng, "Research on instantaneous energy of bilinear system," Journal of Lanzhou Railway University (Natural Sciences), vol. 20, no. 4, pp. 54-59, 2001.

[34] P. Fajfar, T. Vidic, and M. Fischinger, "On energy demand and supply in SDOF systems," in Nonlinear Seismic Analysis and Design of Reinforced Concrete Buildings, P. Fajfar and H. Krawinkler, Eds., Elsevier, 1992.

[35] S.-H. Chen, H.-X. Wei, A.-K. Zhang, and X.-H. Mao, "Computational model and safety criterion of blasting vibration effect based on wavelet packet techniques," Explosion and Shock Waves, vol. 30, no. 4, pp. 377-382, 2010.

[36] T.-H. Ling and X.-B. Li, "Influence of maximum decking charge on intensity of blasting vibration," Journal of Central South University of Technology (English Edition), vol. 13, no. 3, pp. 286289, 2006. 

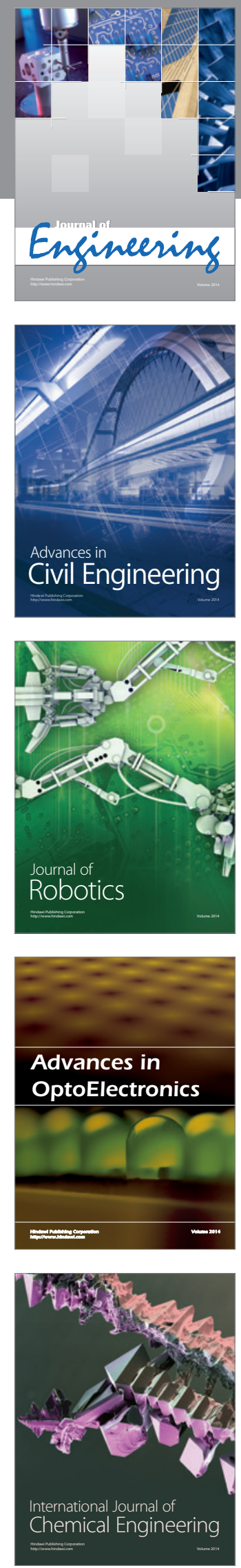

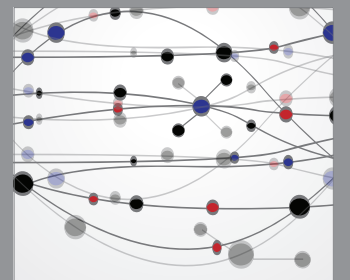

The Scientific World Journal
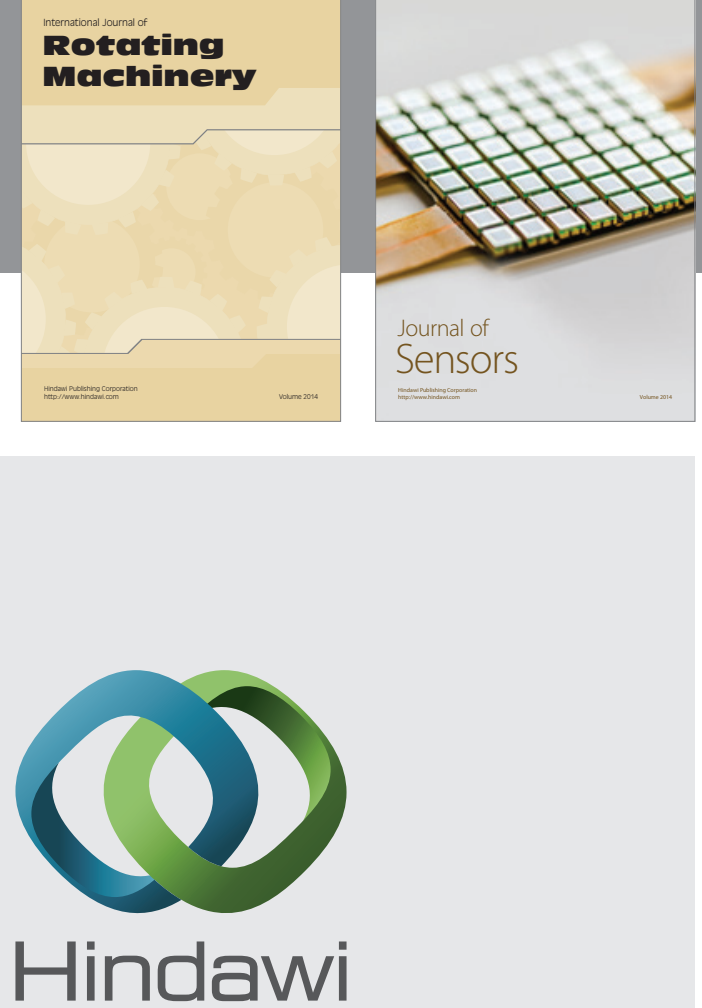

Submit your manuscripts at http://www.hindawi.com
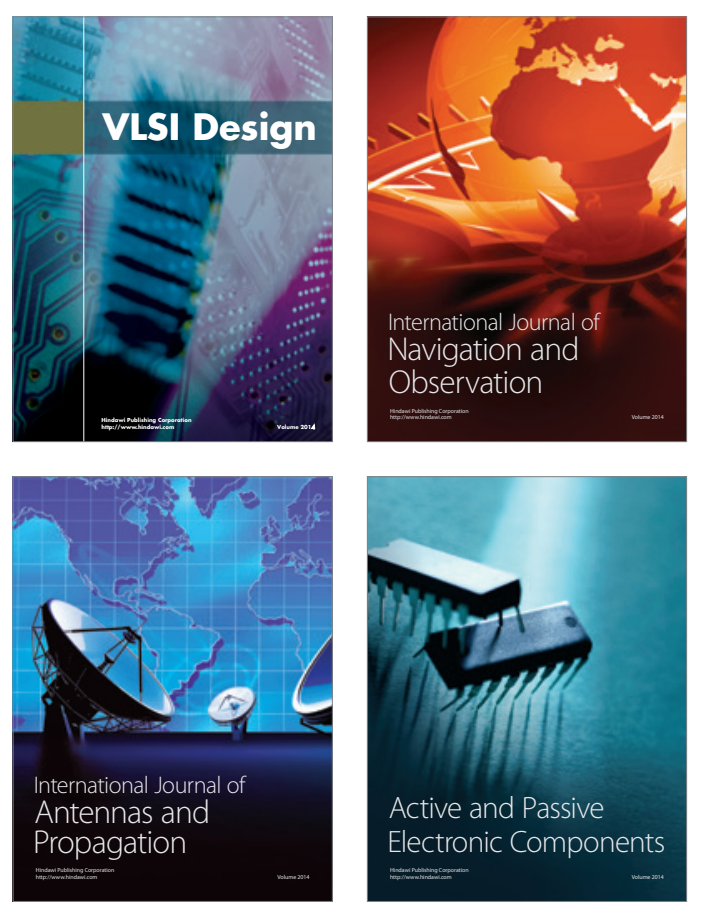
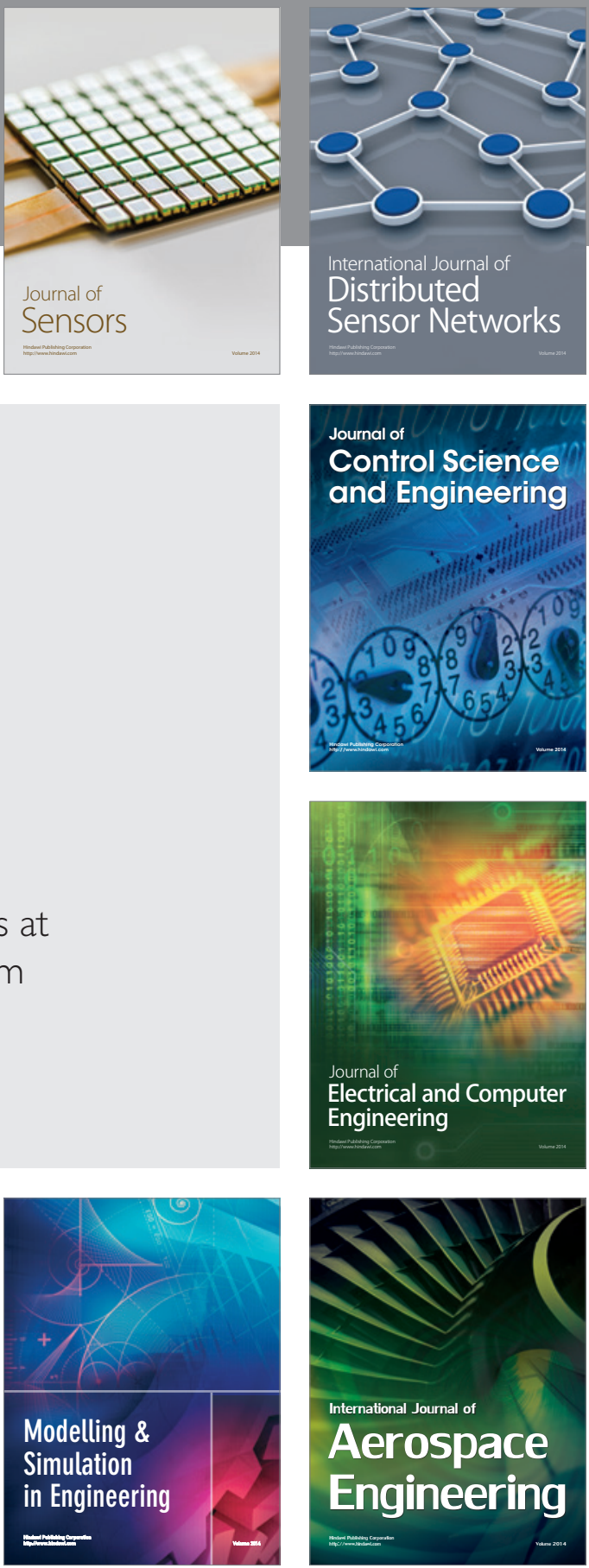

Journal of

Control Science

and Engineering
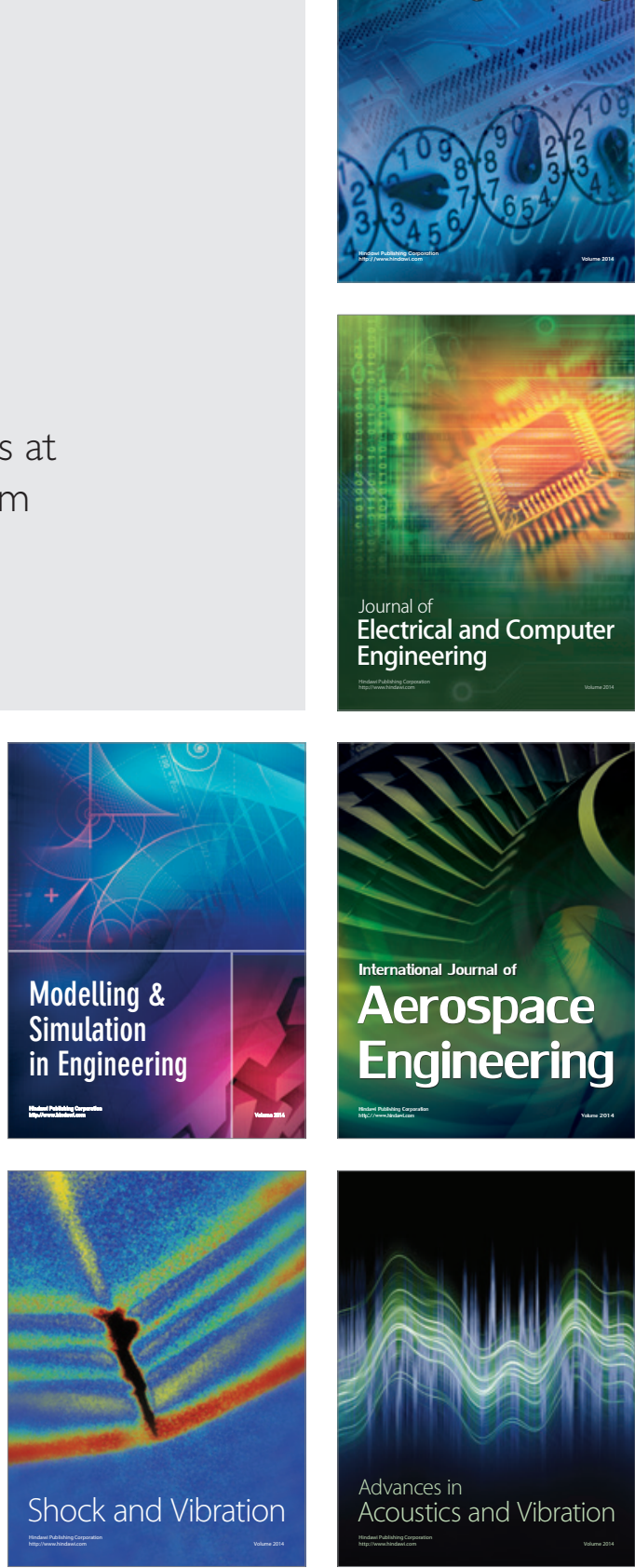